\title{
The Process of Deciding About Prophylactic Surgery for Breast and Ovarian Cancer: Patient Questions, Uncertainties, and Communication
}

\author{
Robert Klitzman ${ }^{1, *}$ and Wendy Chung ${ }^{2, \dagger}$ \\ ${ }^{1}$ College of Physicians and Surgeons and Mailman School of Public Health, Columbia University, \\ New York, New York \\ ${ }^{2}$ Division of Molecular Genetics, Columbia University, New York, New York
}

\begin{abstract}
Many women who have, or are at risk for, BRCA 1/2 mutations or breast cancer decline prophylactic surgery, but questions remain as to how they make and experience these decisions. Our methods consisted of interviewing 32 women for $2 \mathrm{hr}$ each; 19 were tested, 20 were symptomatic. Our results showed that these surgical options forced women to confront questions, involving stresses and uncertainties, regarding: implications of test results, prognoses with and without surgery, and effects of surgery (e.g., on self-image). Given these dilemmas, many women turned to doctors who then ranged in what and how they communicated about these issues, and how strongly they offered input. Some patients felt disappointed at provider non-directiveness, while others found providers too directive. Patients turned to family members and friends, who also ranged in how and what they communicated, and whether they agreed with the patient and/or each other. Many women turned to patient communities, but then had to decide how involved to be, and what information to provide or accept. These data suggest that providers and others may need to be more aware of the series of questions, involving stresses and uncertainties, that these women face, and the complex roles providers themselves may play. These data highlight needs for physicians to be able to address these issues flexibly, gauging patient preferences for information and paternalism (vs. autonomy). These data suggest areas for future research: for example, on how providers decide whether, what and how to communicate about these issues, and how these choices shape treatment decisions.
\end{abstract}

\section{Keywords}

doctor-patient relationship; doctor-patient communication; decision-making; risk and benefits; qualitative research; ethics

\section{INTRODUCTION}

Individuals who have, or are at risk for, $B R C A 1 / 2$ mutations and/or breast cancer face difficult treatment decisions of whether to undergo prophylactic surgeries; but little is known about how these individuals in fact make these decisions-particularly, what stresses

\footnotetext{
(C) 2009 Wiley-Liss, Inc.

*Correspondence to: Robert Klitzman, M.D., Associate Professor of Clinical Psychiatry, College of Physicians and Surgeons and Mailman School of Public Health, Columbia University, Unit 15, 1051 Riverside Drive, New York, NY 10032. rlk2@ columbia.edu.

${ }^{\dagger}$ Assistant Professor of Pediatrics and Medicine.
} 
they face in making these decisions, and what roles, if any, health care providers and others may play.

These issues are important since many women who might benefit from prophylactic surgery do not undergo it. Since ovarian screening is poor, for $B R C A$ mutation carriers, the National Comprehensive Cancer Network recommends prophylactic ovarian surgery by age 35 or by the completion of childbearing [National Comprehensive Cancer Network], and bilateral prophylactic mastectomies for women at high-risk who are interested. Prophylactic oophorectomies and mastectomies have been found to reduce cancer incidence compared to chemo prevention or surveillance [Bermejo-Perez et al., 2007]. For mutation carriers, oophorectomy alone, and oophorectomy with mastectomy have also been found to be the most cost-effective strategies [Anderson et al., 2006]. Yet rates of these surgeries vary, depending on country, and other factors. In the US, for example, of asymptomatic women with BRCA $1 / 2$ mutations, $13 \%$ opted for prophylactic mastectomies, and $13 \%$ for oophorectomies [Lerman et al., 2000]; and 27\%, along with 5\% of non-carriers and $2 \%$ of patients with uninformative results, chose oophorectomies [Schwartz et al., 2003]. However, a Dutch study found that of asymptomatic women with $B R C A 1 / 2$ eligible for prophylactic surgery, $51 \%$ and $64 \%$ chose bilateral mastectomies and oophorectomies, respectively [Meijers-Heijboer et al., 2000]. The reasons for these differences between countries are not clear [Metcalfe et al., 2008a,b]. All surgeries carry potential complications (e.g., from anesthesia), that women must balance as well.

In influencing these rates, several sociodemographic and medical factors have been suggested, particularly BRCA test results, and family cancer history [Ray et al., 2005; Graves et al., 2007], though certain other factors have received less attention. Age, race, and having children may affect uptake and timing, as young women with children may opt more for mastectomies, while older women opt more for oophorectomies [Bradbury et al., 2008]. Psychological factors, particularly perceived risks and benefits and pre-cancer worry, have also been suggested as affecting intentions [van Dijk et al., 2003] and decisions to undergo mastectomies and oophorectomies [Antill et al., 2006; Madalinksa et al., 2007], and genetic testing itself [Helmes, 2002]. Other factors mentioned include trust in the capacity of tests to reduce morbidity [Kram et al., 2006], and patients being "monitors," not "blunters" of information [Miller et al., 2005]. In Canada, rates of surgery vary by region [Metcalfe et al., 2007], though the reasons for this geographic difference are not clear. Qualitative research has suggested that women may choose oophorectomies based on additional factors such as risk perceptions, cancer witnessed in family members, family obligations, concerns about fertility and menopause, and fear of surgical complications, [Hallowell et al., 2001]. In general, women must balance potential benefits of anxiety-reduction against potential complications of surgery [Tiller et al., 2002].

But questions persist concerning the decision-making processes involved-for examplehow women actually approach and balance these various issues and needs, and make these difficult choices and trade-offs of whether or not to undergo these various preventive surgeries, and when and how. Though potential factors have been suggested, as above, the decision-making processes entailed remain unclear. Given that rates of surgery are still relatively low among younger women for mastectomies, and among older women for oophorectomies, critical questions persist of how women view and experience these decisions, and what, if anything, might be done to assist women in making these decisions.

In shaping other medical decisions, relationships with providers and family members have been found to play critical roles [Klitzman, 2008]. For example, for another genetic disorder, Huntington Disease, familial contexts can shape experiences of being at risk [Cox and 
McKellin, 1999], and testing, disclosure and reproductive decisions [Klitzman et al., 2007a,b,c].

We conducted a literature search, and found that only a few studies concerning testing — but almost none concerning treatment-for $B R C A 1 / 2$ have explored interactions with providers. Several studies on communication about $B R C A$ testing suggested that testing decisions and understandings of genetic risk operate in dynamic interpersonal relationships and are subjective [Gifford, 1986]. Most, but not all BRCA mutation carriers have discussed their results with a doctor or healthcare provider [Botkin et al., 2003].

Patients' subsequent approaches to treatment as a result of such testing may similarly be subjective, and be shaped by social contexts, but these phenomena (e.g., interactions concerning breast cancer treatment) have received relatively little attention. In one of the only investigations we found that broached this area - a study of African-American women -carriers were more likely than non-carriers to discuss results with primary care providers after testing. Yet carriers usually did not communicate with providers about prophylactic mastectomies and oophorectomies (i.e., only $24 \%$ and $43 \%$, respectively, did so) [Kinney et al., 2006]. Premenopausal women have also reported unmet information needs before and after procedures [Meiser et al., 2000]. Similarly, though tamoxifen has been suggested as a possible preventive therapy among mutation-positive women, most women in one study said that their doctors had not provided them with enough information to consider it [Metcalfe et al., 2005].

A handful of studies have explored views of providers concerning available treatment options. For example, more general surgeons than plastic surgeons or gynecologists (85\%, $47 \%, 38 \%$, respectively) thought prophylactic mastectomies had a role in caring for highrisk patients $(P=0.0001)$, but only $39 \%$ of general surgeons, and $18 \%$ of gynecologists ever recommended it $(P<0.001)$ [Houn et al., 1995]. Among French doctors in 2000, only $18.7 \%$ thought prophylactic mastectomy acceptable for a women with BRCA 1/2 [JulianReynier et al., 2000]. Physician views may affect patients in several ways. For example, in one study, the most common predictor of regrets post-surgery was discussion having been initiated by the provider, rather than by the patient [Payne et al., 2000].

Though studies suggest that enhanced genetic counseling can help with decision-making [Miller et al., 2005], there is a shortage of genetic counselors. The US has only about 2,000 genetic counselors, not all of whom are practicing at any one time [American Board of Genetic Counseling, 2008]. Decision-making aids have been developed for patients [Kaufman et al., 2003; Lobb et al., 2006], but it is not clear how these do or might actually alter interactions. Similarly, given the many psychological factors involved, it has been suggested that counseling psychologists become involved in helping patients with these issues [Kaut, 2006]. But the roles that physicians actually now play remains uncertain.

From a theoretical perspective, in research thus far on patient decision-making related to genetics, cognitive models have predominated. For example, the Health Belief Model suggests that an individual's health behaviors are shaped by perceived susceptibility, disease severity, and costs and benefits of the behavior [Rosenstock et al., 1988]. The Stages of Change Model [Prochaska et al., 1992] suggests that individuals proceed from being unaware, to aware but unengaged, to engaged in a health decision.

But in both of these theoretical models, it is not clear whether providers and others influence these factors or stages, and if so, when, how and to what degree. Providers might potentially affect such awareness and beliefs, but it is not clear if they in fact do so, and if so, how. 
Thus, we decided to explore how exactly women experience and make these difficult decisions regarding prophylactic surgery for breast and ovarian cancer: what stresses they face in the process, whether social contexts with providers and others affect these decisions, and if so, how.

\section{METHODS}

\section{Sample}

To understand most fully the range of issues and experiences that women at risk of breast cancer face concerning prophylactic surgery, and the roles and implications of these issues in these women's lives, we recruited women who differed in both testing status and symptom status. Thus, we included women who were both symptomatic and asymptomatic, and both tested and untested. Among those who were tested, we included both those who had and those who did not have a mutation. To recruit participants, we distributed information about the study through breast cancer clinics, other breast cancer studies at our institution, a newsletter to a breast cancer family registry, flyers displayed on bulletin boards of our institution, and word of mouth. Individuals contacted the principal investigator if they were interested. As revealed in their narratives, many of these women had over time occupied more than one of these categories. For instance, all tested women were initially untested, and all symptomatic women had initially been asymptomatic. Interviewees all discussed both their past and present views and experiences regarding these issues. We included women who were able to give consent and spoke English. As indicated in Table I, we interviewed, for $2 \mathrm{hr}$ each, a total of 32 women, including 20 who have had breast and/or ovarian cancer, and 12 who have not; and 19 of whom have had BRCA 1/2 testing ( 8 mutation-positive, 10 mutation-negative and 1 indeterminate result). Of the symptomatic women, 14 were tested ( 7 BRCA 1/2 positive, and 7 mutation negative).

With each participant, the PI conducted a confidential in-depth semi-structured interview concerning experiences of having, or being at risk for breast cancer. Interviews were conducted in the PI's office and took approximately $2 \mathrm{hr}$, though varying somewhat in length. The Columbia University Department of Psychiatry Institutional Review Board approved the study, and all participants gave informed consent. Relevant sample questions from the semi-structured interview guide are attached (see Table II), through which we sought to obtain detailed descriptions of the process of individuals' view and decisions concerning testing treatment and related issues.

On theoretical grounds, Geertz [1973] has advocated studying aspects of individuals' lives and social situations not by imposing external theoretical structures, but by trying to understand individuals' own experiences, drawing on their own words and perspectives to obtain a "thick description." Hence, to understand most fully the range of factors and issues that may be involved in genetic testing decisions, we used qualitative methods.

\section{Data Analysis}

We have adapted elements from Grounded Theory, as described by Strauss and Corbin [1990], because we were interested in understanding a complex social process. Specifically, grounded theory involves both deductive and inductive thinking, building inductively from the data to an understanding of themes and patterns within the data, and deductively drawing on frameworks from previous research and theories. For example, interviewees introduced topics such as interactions with providers that were then explored further in these and other interviews. Our approach was informed constant comparison in which data from different individuals were compared for similarities and differences to see whether these suggested hypotheses. Transcriptions and initial analyses of interviews were done during the period in 
which the interviews were being conducted and helped guide the interviews. Interviews were conducted until "saturation" was reached (i.e., "the point at which no new information or themes are observed in the data") [Strauss and Corbin, 1990; Guest et al., 2006].

Once the full set of interviews was completed, subsequent analyses were conducted in two phases, primarily by the PI together with a research assistant (RA) who had social science training. In phase I of the coding, the PI and the RA independently examined a subset of interviews to assess factors that shaped participants' experiences, identifying categories of recurrent themes and issues that were subsequently given codes. These two coders assessed similarities and differences between participants, examining themes and categories that emerged, ranges of variation within categories, and variables that may be involved. The coders systematically coded blocks of test to assign "core" codes or categories. While reading the interviews, a topic name (code) was inserted beside each excerpt of the interview to indicate the themes being discussed. The coders then worked together to reconcile their independently developed coding schemes into a single scheme, developing a coding manual and examining areas of disagreement until reaching consensus between them. New themes that did not fit into the original coding framework were discussed, and modifications were made in the manual when deemed appropriate.

In the next phase of the analysis, we subdivided thematic categories into secondary or subcodes, and then refined and merged these, when suggested by associations or overlap in the data. Codes and subcodes were then used in analysis of all of the interviews. Major codes included, for example, occasions when providers offered input to patients concerning surgery. Subcodes were conceptual and thematic subdivisions of these larger categories and included reactions and behaviors of patients (e.g., patients' responses to input from physicians). To ensure coding reliability, these two coders analyzed all interviews. We examined any areas of disagreement until consensus was reached. To further enhance trustworthiness, we compared themes in the data with existing literature concerning breast cancer and other genetically associated diseases, as discussed above. These data also appeared to have a certain "face validity"- that is, they seemed to be consistent with clinical experiences and previous research in this and related areas. We have presented below text from the interviews to allow readers to judge these data for themselves as well.

Management recommendations for risk-reducing mastectomies and oophorectomies differ. Yet clinical guidelines for both leave much room for questions for women. For oophorectomies, women have to decide exactly how long before turning age 35 they can wait before undergoing surgery. Prophylactic mastectomy decisions pose difficult choices as well, weighing risks of disease versus risks of surgery; and balancing desires to avoid each set of potential dangers. Hence, though the issues vary in some regards, we found that in contemplating each type of surgery, common themes often arose, as described below. Women faced critical similarities: in both instances confronting troubling dilemmas, having to weigh conflicting psychological desires, and encountering similar patterns of challenges in communicating with providers and others. Differences emerged as well, as we have indicated, but overall, the similarities appeared to far outweigh the differences.

Moreover, many women faced decisions concerning both of these prophylactic operations as well as surgery for treatment-either simultaneously or sequentially. Women's experiences confronting one procedure often thus shaped their subsequent decisions concerning other operations. Hence, we have decided to present together the issues that these surgeries pose, rather than isolating and presenting issues concerning just one prophylactic procedure, out of context from the other. 


\section{RESULTS}

Overall, as shown in Figure 1, in these decisions, women confronted, and struggled with, several sets of uncertainties that generated difficult stresses. They wrestled with a sequential series of agonizing treatment decisions-for example, whether to undergo these treatments, and if so, which, when and how. As a result, they sought and received input from providers, family members, friends and the breast cancer community. These stresses and subsequent interactions could potentially shape patients' ultimate treatment decisions. Yet complexities arose concerning this communication. As indicated below, interviewees discussed their own experiences as well as those of family members (e.g., sisters) and friends in confronting these issues. Passages of text from the interviews, below, illustrate these issues, often highlighting simultaneously more than one theme (e.g., as a patient communicates with a doctor about a treatment decision), as described.

\section{SERIES OF STRESSFUL QUESTIONS FACED}

\section{Whether to Undergo Surgery}

As shown in Figure 1, in making these decisions, women faced a series of questions, involving stressful uncertainties of: whether to undergo genetic testing, whether they would develop cancer if they had the BRCA 1/2 mutation or not; and whether to undergo a lumpectomy or mastectomy, prophylactic mastectomies, breast reconstruction, and/or oophorectomies.

Dilemmas of whether or not to undergo surgery are exacerbated by the fact that prognoses are uncertain both with and without surgery; and operations can have unpredictable side effects. Hence, initially, when becoming aware of the notion of prophylactic surgery, many women were wary.

Many considered or pursued testing precisely because it would give them the option of contemplating prophylactic surgery if they were to test mutation-positive. Some tested to know if they should undergo prophylactic surgery. Others avoided testing because of treatment imperatives they would then have to face. One woman, a professor, described how views about eventual prophylactic surgery arose during initial testing decisions.

So far, I have opted to not get tested. It's an open question. I asked my oncologist, "What difference would it make in my treatment?" She said, "At some point I would say: take out your ovaries, if there were a genetic link." So, do I want to have my ovaries taken out, having been genetically tested? Or, do it prophylactically even without the testing? BC7

She poses a series of questions with which she still wrestles. She continued, about her support group,

Most of us have not been tested. Other perspectives are: I want to know if I'm going to get it again, if I should have my ovaries out, or have a prophylactic mastectomy. BC7

Even some who decided not to undergo testing, nonetheless considered prophylactic surgery.

Of note, some subjects whom many physicians may not consider to be appropriate for testing were nevertheless tested by their providers, suggesting that testing may occur anyway in various cases. These individuals tested because they "just wanted to know," and/ or their insurance would cover it since they had already had cancer, and they felt that the information might be helpful to their adult offspring who had not yet had cancer. These 
offspring could face stigma and discrimination, if tested themselves and found to have a mutation. In addition, it is possible that some providers may not fully understand when testing is versus is not indicated.

\section{Which Surgeries to Undergo}

As described elsewhere here, women faced decisions about whether to undergo a series of surgeries_-prophylactic mastectomies (possibly followed by reconstruction), and oophorectomies, in addition to operations to remove existing lesions-for example, lumpectomies and mastectomies.

\section{When to Undergo Surgeries}

Uncertainties arise, too, of when to undergo surgery - weighing desires to delay in order to become comfortable psychologically with the possibility versus desires to eliminate cancer worries and needs to stop possible disease progression as soon as possible. Particular questions surface of how long they could wait, after having a mastectomy, before undergoing oophorectomies, without deleterious consequences.

I'm pretty much certain that I'll have my ovaries removed ... My oncologist said I don't have to have it done now. They're suggesting: before I'm 50. I'm 40. Could I wait 10 years? As I get older, the incidence of ovarian cancer increases. I'm not sure if I'm eliminating any unnecessary anxiety by doing it sooner rather than later. But, being through what I've been through this year, I feel that if I were to do it now, I could at least put this chapter in my life behind me in some way, and not worry. I'm concerned with getting a cancer they can't detect. And I don't want to be under the magnifying glass the rest of my life. I have these mixed feelings about it: real confusions in my mind about what to do. BC6

These women experience these decisions in the context of their on-going risk and/or illness over time, adding stress since each decision occurs as part of a langer sequential series of choices. Hence, many sought to postpone decisions, though doing so can represent, in part, denial as a way of coping with the stresses involved. As another woman, who had bilateral mastectomies and was now contemplating an oophorectomy, said,

I don't want to think about it. I picked a number: when I hit 45. Next year. I guess I haven't decided. I mean, I've decided, but I keep on putting it off. For doctors, it's an easy decision. They say: "take it out right away." That's fine, but for me, it's like: “Can't I just wait? I've gone through enough." I understand it's increased my chances of getting ovarian by $40 \%$ over a woman's lifetime. BC4

She distinguishes physicians' cavalier stances about these procedures from her own hesitation due to her history of illness, including a mastectomy. This past operation thus frames her outlook toward a possible oophorectomy. Given these difficult tradeoffs, though she understands the medical risks, she tries to delay surgery, thinking of excuses.

I wanted to wait a year after surgery. Then, "I'll wait until I go into menopause."

Well, now I'm there. I'm going to constantly give an excuse. BC4

She suggests a psychological process, involving a series of rationalizations, which can serve continually to delay the operation.

\section{What Side Effects May Result From Surgery}

Women face ambiguities, too, about the possible deleterious effects of surgery-including subjective concerns of whether it will harm physical attractiveness, sexual experiences and relationships, and views of one's body or of oneself. To answer these questions definitively 
is hard. One woman, with a strong family history that included a sister, was very anxious about her risk, though she had not yet decided to undergo testing. She said,

Over the last few weeks, I've been looking at other women's breasts, thinking, "Is it really that big a deal?" wondering what some of the sensations are going to be like. Arousal in your nipples is not going to be there. But how much does that interfere with having a loving and caring intimate relationship? BC15

Uncertainties arise about the effects of these on both sexual experiences, and romantic relationships.

\section{Communication About Stresses}

Given these quandaries, women generally sought and received input from several groups of others, including health care workers (HCWs), friends and family, and breast cancer communities. As shown in Figure 1, issues arose concerning several aspects of communication from each of these groups-factors that shaped both how assistance was offered and received.

\section{Communication With Doctors}

What doctors communicate-HCWs offered input, though these interactions often proved complicated. The uncertainties discussed above led many women to want clear, unambiguous medical opinions. Given the complexities and subjectiveness of decisions about prophylactic surgery, many physicians and other individuals did not feel comfortable giving such unequivocal input. The very personal aspects of these stresses made many providers and others hesitate or feel unable to offer clear advice. As one woman, who faced decisions of whether to undergo a lumpectomy versus a mastectomy, said:

I called my internist, because she's a good friend, to help me make that decision.

But she just felt she really couldn't. BC23

Physicians may feel torn-wanting to help patients, but recognizing that in the long run, giving a simple definitive opinion may not be best.

Patients may recognize that such certain input may ultimately be elusive. She continued:

Sometimes we want to hear that there is one answer, but there is none. Sometimes I wished somebody said, "This is how you do it. If you have Strep throat, this is the pill. That's it. End of story." Whereas with this, you have to make a judgment call. A lot of information comes at you fast and furious. Sometimes it's a lot easier just being a little kid: Your mother says this is what you're having for dinner, instead of you having to go to the supermarket and decide. BC23

She underscores the stress and difficulty of having to confront these dilemmas, and assess relatively large amounts of information without sufficient guidance, while desiring certainty, which may not be possible.

Clearly, differences can emerge when surgeons work with newly diagnosed women with cancer (where direct approaches may be well-suited) versus women contemplating prophylactic operations (where non-directive discussions may be more appropriate). Yet this woman suggests how ambiguities arise even for this decision between lumpectomy versus mastectomy, which may involve both therapeutic and prophylactic considerations.

Doctors may vary in not only how directly they make their recommendations, but also in whether they present other treatment options. Given the exquisite sensitivities involved, with threats to the body and with the symbolic meanings of breasts and ovaries, women 
frequently wanted at least to hear about possible alternatives, and to have these options addressed as sensitively as possible. Yet, these patients often felt disappointed.

I left the first breast surgeon because he said, “Ok, here's what we do: we're going to remove your breast, and you're going to have chemotherapy and potentially radiation." My husband and I sat there saying, "We don't need it sugarcoated, but what about alternatives?" He said, "You could pursue these, but ..." In the end, I ended up doing what that doctor said, but with a breast surgeon who worked with my Integrated Medicine Oncologist - they had worked together before, and respected each other. BC6

This first doctor ignored a holistic approach and complementary and alternative medicine (CAM) that the patient valued. As she explained,

I've been working with an Integrated Medicine Oncologist, and the belief system with an Integrated Medicine Oncologist is very different than with a traditional and conventional doctor. Part of my protocol, besides doing the conventional stuff, has been to integrate meditation, acupuncture, massage therapy for stress reduction, lymphatic massage, and a variety of supplements, not just vitamins, but antioxidants and extra Vitamin C, algae and very large doses of dehydrated vegetables and fruits.

Many women felt that such alternative adjunct therapy was important, even if doctors dismissed it. Nonetheless, a physician's presentation of, or openness to, such alternatives may enhance patients' satisfaction and trust.

How doctors communicate-Clearly, physicians varied in the degrees to which they provided input versus left the decision up to the patient. Physicians may not answer what to do, due to the uncertainties and subjectivities involved, and instead leave much of the decision-making up to the woman herself-including choices among surgical options (e.g., lumpectomy vs. mastectomy). Yet these difficult options can overwhelm patients.

The doctor said there might be something in my nodes, so it was my choice to have the breast removed or leave it. After I found out I had breast cancer, I decided to have it removed. It was very hard-like the world was coming down on me. BC21

These decisions can thus feel onerous-even crushing.

On the other hand, in the face of these uncertainties and sensitivities, some physicians may provide input too readily or forcefully. Particularly for oophorectomies, given their considerable reproductive and psychological implications, doctors can appear insensitive regarding the stresses involved, not seeing these issues from patients' points of view. Doctors varied in not only the content and directiveness of their input, but their tone and sensitivity. These concerns arose for surgery as both treatment and prophylaxis.

For doctors, it's just another day at the office. They don't consider the patient, and what she is going through. When my sister was getting the mass removed from her ovary, the doctor said, "We'll go in, scoop it out. We'll be out in a minute." Scoop it out? It drove me insane. He was "one of the best", but I feel so bad for any woman who goes to him. I've seen other doctors like that, too, male and female, it didn't matter. BC1

Relatedly, doctors may appear insensitive not only in what information they presented-but where (in what context) they presented it. As one woman said about an ultrasound that found ovarian cysts, 
This doctor tried to discuss with me the results of the sonogram over the phone. I said, "Hi, doctor," and suddenly I'm being told about this stuff. I didn't want to hear it over the phone. I don't think she was a good doctor. I don't see her anymore. My experience was bad. BC25

The information provided by this doctor may be scientifically valid, but the patient did not like how it was conveyed - specifically, the context—both over the phone, and without emotionally sensitive framing of the information (i.e., without any introduction to contextualize the information in order to try to lessen the trauma). Such perceived insensitivity can be unexpected and surprising, coming from a relatively young female physician. Such patient reactions, though subjective, are nonetheless important, potentially shaping patient satisfaction, trust, and treatment adherence-and thereby treatment outcomes. Of note, here, too, the gender of the physicians did not seem to matter.

When doctors communicate-Given these vagaries, doctors' timeframes also differed in both raising the topic of surgeries, and recommending that patients undergo these procedures. Physicians ranged in the degrees to which they raised time considerations (e.g., pushed patients in these decisions). Some patients felt urgency from doctors to undergo surgery, and perceived insensitivities concerning the time dimensions involved.

My gynecologist and oncologist are ok with waiting. My breast doctor is the only one pressuring me. BC4

The fact that this patient felt pressure is important, as it suggests possible elements of coerciveness that could restrain a patient's feelings of autonomy. Questions emerge, too, of tensions physicians may confront between autonomy versus paternalism (i.e., doctors encouraging what they think is best).

HCWs may face conflicts, too, in deciding when initially to raise options of surgery, in order to allow patients to prepare psychologically as much as possible. The possibility of prophylactic surgery emerges not only after genetic testing is conducted, but beforehand as well, when considering genetic testing itself-as a hypothetical. Yet women may see providers as presenting options either too early (e.g., before women undergo genetic testing) or too late. HCWs may want to prepare patients for the possibility of surgery by raising the topic before genetic test or biopsy results are available. Yet women may feel that these conversations then occur prematurely.

Before I got my test results, the doctor jumped ahead to tell me: if you're positive, you should just take out your ovaries. I wasn't sure. I didn't think I wanted kids. She said, "Then it's easy. You'll just take the ovaries out." She seemed very confident. I thought, "What?! You don't even know what I have! Why are you telling me that?" BC25

A patient may think about these questions and objections, but not feel comfortable expressing them to a provider. This discomfort could thus impede patients in giving feedback that might otherwise prompt doctors to communicate further and clarify treatment rationales. Thus, physicians may need to be careful in framing their input, explaining their reasons for broaching these topics - for example, not to cause anxiety prematurely, but to prepare patients by discussing the options as much in advance as possible.

Why doctors communicate as they do-Patients suspected that at times, institutional factors hampered provider communication. Some patients felt, for example, that providers may defer from being more involved in these decisions in part because of legal liabilities and/or insurance concerns. 
If they say, "this is what you do", and things backfire, somebody's going to turn around and sue. No doctor wants to take that legal risk. BC23

Hence, patients at times felt that doctors may not discuss certain options unless patients specifically asked about these.

The doctor recommended a mastectomy only on the sick breast. I asked, "How about this other one? Do I run the risk of developing something there?" The doctor said, "Yes, it's a good idea. I'm glad you asked: I'm not allowed to raise it by myself." She couldn't recommend it without me asking for it. BC28

This patient felt that insurance or other constraints may limit the doctor's options, though in this particular instance, the precise nature of these constraints was not wholly clear. Nonetheless, this woman highlights how patients felt that the larger health care system could at times restrain physicians.

Other factors may play roles here as well. Doctors' personalities may prove important, yet as suggested earlier, physician age and gender may not always predict sensitivity toward these issues. As mentioned above, a physician may act insensitively despite being young and female.

\section{Implications}

As a result of physicians' low levels of input, finding the "right" physician can be hard, further exacerbating stresses. As a result, women may "shop around" for a doctor they like, though they did not all have flexible insurance plans or out-of-pocket funds to allow them to do so. Difficult tradeoffs thus arose in choosing doctors. Even with a lumpectomy, questions emerged as to how extensive an operation to have. As one patient, who was a lawyer, said,

I went to four different surgeons. My parents and partner felt that the first one would be too busy. Another was too paternalistic. A third one wanted to take out a bunch of nodes, rather than do a sentinel node biopsy, so I eliminated her, though I liked her a lot. BC7

Women have to consider what a doctor recommends, as well as how and when he or she recommends it. This woman balanced one physician's bedside manner versus treatment recommendation, and weighed the former over the latter. Variations in physicians' styles, timing and recommendations thus complicate these choices. Women, in turn, vary widely in weighing these diverse factors, making it difficult for providers to know a priori how best to approach these issues with each individual patient. This woman suggests, too, the degree to which such "shopping" may occur. In her case, she assessed four physicians.

\section{Communication With Family and Friends}

Given these stresses and often disappointing interactions with providers, women frequently turn to others-especially, initially, family members and friends. Yet these additional interactions, too, range considerably.

How family and friends communicate-Family members and friends can differ, as do $\mathrm{HCWs}$, in being either too aggressive and "opinionated" or too removed. One woman felt pressured by her employer.

My boss always pushes me to get the surgery. She has Multiple Sclerosis. Living with her situation, unable to do anything about it, she thinks, "are you crazy? You can do something! Do the surgery. And don't have the reconstruction-do it the simple way." But I just don't think I can deal with a double mastectomy, seeing what it looks like. BC8 
These highly personal and subjective issues can lead women and their close social supports to vary in viewing these choices. Ultimately, this patient underwent an oophorectomy, but not a mastectomy, choosing one type of prophylactic surgery, but not another. She illustrates, too, how patients confront, and receive input regarding not simply one isolated decision, but several linked ones—-here, of mastectomy and reconstruction.

Whether they agree or disagree-A patient's main social supports can agree or disagree with each other and/or the patient, creating conflicts that the patient must then address, balancing these competing views. As one woman said about a possible oophorectomy,

My siblings are leaning towards "no: why have surgery when you might not need it?" My friends are leaning towards "yes: cancer is bad. If you can lower your chances, why not?" BC27

Patients must then weigh such clashing arguments against each other, negotiating between these views, and the proponents of each. Patients may remain undecided what to do.

Other individuals can prove vital in bolstering a woman's own preference, and deferring to it. For instance, a strong relationship, and support from a partner can help minimize surgery's possible impediments (e.g., to a woman's romantic life).

My partner's mother and sisters had breast cancer. His mother had a radical mastectomy. He had melanoma, and his second son had leukemia. My doc asked my partner, "What do you think about it?" He said, "She's going to have bilateral mastectomies. I'm not going to stand in front of this freight train." BC15

He respected and valued her autonomy, in part due to his own experiences and those of his immediate family members-all of which then made it easier for her. Thus, these interactions can be highly dynamic; and a spouse's or other family members' own past personal experiences can in turn shape a patient's experiences as well.

Other women may not be as fortunate to have as reinforcing and knowledgeable a significant other, though in the end, families and close friends generally upheld, rather than opposed patients' preferences. Spouses, in particular, usually saw their opinions as secondary to the patient's own. Family and friends may voice strong opposition but, in the end, respect, more than do physicians, a "feminist" position - that ultimately, a women's decisions about her body are her own.

In the end, despite the fact that my boyfriend was so against it, and people said, "Oh my God, it's so drastic," it was my decision. It's my life. Nobody else's. A guy's perspective is irrelevant-purely sexual, or selfish. Basically, this has nothing to do with him, and everything to do with me. If any woman is thinking about what a guy is thinking, she's foolish. Ultimately, it's her life. BC14

\section{Communication With the Breast Cancer Community}

Given these stresses and often suboptimal inputs from providers and, potentially, family members and friends, many women also turned for assistance to communities of other women confronting breast cancer. These communities—both formal and informal—could fill in gaps left by families and providers. Yet, several sets of issues arose here, too.

What communities communicate-Within breast cancer communities, women vary in what information they share and how they do so. Debates about these surgeries occupy much on-line communication, and information from websites and patient advocacy organizations (either on-line or through support groups or meetings) can aid these decisions. 
One woman, for example, had undergone an oophorectomy, but has had difficulty facing the prospect of additional surgery - a mastectomy.

On-line, the biggest issues are whether to be tested or not, and have surgery, once you know you have this gene. Some women are really pro-surgery, and have done everything possible. Others feel they don't need to go to such extremes. Women who haven't had cancer, but have mothers or sisters who have, go to extremes and have preventive surgeries. I give them a lot of credit; that's very brave. I haven't been able to come to terms with surgery. BC8

Hearing about others' decisions can be helpful, though women saw themselves as varying widely in key factors such as tolerance and acceptance of risk. Patients can take strong positions (e.g., being "pro-surgery") and do what others may consider "extreme." Nonetheless, these interviewees generally felt that ultimately, individuals do and should weigh these choices based on their own courage and personal concerns.

Individuals in communities can vary and clash in their opinions, and potentially sway each others' decisions. One woman with a strong family history spoke to other women when initially considering testing and its implications. She had contemplated the possibility of prophylactic surgery as a reason to undergo testing.

Other women have had double mastectomies — because their mothers died earlyand feel it saved their lives. For them, it made sense; so I did hear some positive stories to counter this insane invasive surgery. BC25

This woman decided to pursue testing, and turned out to be mutation-negative.

The specific venue can affect these parameters. For example, the Internet offers certain advantages over direct face-to-face interactions, providing large amounts of information (including, importantly, photographs of surgical results), and permitting anonymity. Within these communities, members can share intimate experiences and even images of breasts after surgery. Frequently, norms prevail that prioritized such sharing, altruism and communitarianism over protection of personal confidentiality. This communality forges and in turn further strengthens social connections. Women may not even see options to such sharing.

If someone asks me, I'd probably show her my breasts. How great they look ... I show everybody who wants to look. I'm not shy. How can you be? BC14

The breast cancer community served critical functions, providing key information that physicians and often family and other friends did not. Patients frequently sought as much information as possible, and hence valued the vast amount of data and experience, both visual and verbal, available on-line. A strong sense of community exists even on-line, encouraging and facilitating patients in helping each other. Nevertheless, patients ranged in the degrees to which they were willing to forego confidentiality in exchange for additional social support.

Women differed, too, in the amounts and kinds of information they sought. Some women were "highly proactive," looking at outcomes even before receiving their own genetic test results, in order to help decide what prophylactic or other surgeries to undergo. Patients may even shop on-line for surgeons before receiving their genetic test results. Even before testing, one woman said,

I went to some of the big plastic surgery sites. You can go through lists of hundreds of surgeons, and look at their patients' pictures before and after. I looked at the pictures of people who had had prophylactic work done vs. mastectomies only after 
developing cancer. The prophylactic ones looked a hell of a lot better. I even looked at the different techniques. I was thinking the flap would be good. BC26

She wanted to see other women's results herself-highlighting the importance of visual, not only verbal information in confronting these multiple uncertainties.

Someone might say, "Why not ask your doctors for recommendations?" But I wanted to see what kind of work they do-what reconstructed boobies looked like in both cases, if there was a difference. You had more choices if you did it sooner -making it look better. BC26

How to assess information-As suggested above, women have to assess the content and validity of information they receive, which can be difficult. Within these disease communities, patients have to judge each others' views in the contexts of possible biases, personal preferences and personalities. Patients varied in how much to accept versus question information accessed-particularly on-line from anonymous sources.

How involved to be-Women faced as well dilemmas of how much, and in what ways to participate in these communities. Not all women entered these groups (thereby giving and receiving information) to equal degrees. Within these social contexts, the experiences of others who had undergone surgeries can be helpful and/or frightening. Women may become very involved, seeking much information to help in making decisions. They read about, and reflect on, other women's choices. Patients may benefit from this input initially, or at later stages of their diagnosis, and become less involved at other times. These communities could expose women to patients with more advanced illness, which can potentially be upsetting, though the women here generally appeared able to modulate their degree and type of involvement to remain comfortable with it.

Several patients became very active in these disease communities, with these involvements coming to structure much of their lives; yet these engagements, while helpful, can prompt criticism from others. Family members and friends may feel that these activities take too much time. One woman's relatives did not understand the benefits she received from participating, and they chastised her instead to "get a life."

\section{DISCUSSION}

These data elucidate the series of questions that women face, involving stresses and uncertainties, when confronting the possibilities of prophylactic surgeries for breast and ovarian cancer, and the difficulties that women confront in communicating about these dilemmas with providers, family and friends, and breast cancer communities. Women encounter questions of whether to undergo surgery, how to assess uncertain prognoses related to genetic tests and surgery, which surgeries to undergo (e.g., prophylactic mastectomy, reconstruction, and prophylactic oophorectomy), when to undergo these operations (i.e., now vs. delaying); what side effects may result (e.g., harm to physical attractiveness, sexual experience/functioning, romantic life, and views of one's body and self), and how to decide (e.g., whether to accept or reject input from HCWs and others). These issues concerning prophylactic surgeries could even shape decisions of whether or not to undergo genetic testing.

These dilemmas lead many women to seek guidance from doctors and others who appeared then to vary in what and how they communicated about these issues. These potential social supports ranged widely, and often defer from offering strong input for several reasons. These decisions involve deeply personal and hence subjective values. Ambiguities are inherent in risks of both surgery and future cancer. Providers may also be constrained by 
limitations of the health care system, related to insurance or liability concerns. While some women felt disappointed that a physician was not more directive, others rejected doctors' input as too forceful or definitive, and hence insensitive.

Given, in part, that interactions with providers may not be wholly satisfying, women often turn, too, to family members and friends. Yet these social supports can also range widely in how and what they communicate, and whether they agree or disagree with the patient and/or each other. Input from these non-physicians may not be supported by clinical expertise, and patients may face stresses in deciding whether or not to agree with, and/or follow, these social supports. In the end, family members and friends may buttress and accommodate these women's own choices more than physicians do. Yet tensions could nonetheless arise. Many women felt dissatisfied with the input they received from family and friends. Yet these social supports may also feel frustrated, caught in a double bind, being unable to offer more definitive advice—wanting, but feeling unable to do so.

Given needs that are not otherwise met, many women turn, too, to breast cancer communities. But women then have to decide how involved to be, what information to provide or access, and how much to accept or question the information they obtain.

Though factors have previously been suggested (e.g., genetic test results, and family history) that can affect decisions to undergo surgery, the present data suggest that these considerations can in fact be highly complex, embodying uncertainties that are difficult resolve, involving stresses that women struggle to understand and weigh, and that can impede and/or delay decisions.

These data have several implications for enhancing provider education and doctor-patient interactions, suggesting how many providers can potentially improve what, how, when and where they communicate with patients about these areas. Physicians may need to be more sensitive to these issues, and be prepared to be able broach these areas, related to sexual functioning, reproductive plans and physical attractiveness, to help patients with these decisions, acknowledging these subjective and taboo-enshrouded concerns legitimate. Providers may also need to be more aware of the fact that they may view the form and content of their recommendations and patterns of communication far differently than do their patients.

Yet these findings pose inherent challenges as well. Though genetic counselors are trained to be non-directive, medical education has a long tradition of relative directiveness and paternalism. Generally, doctors are trained to be more directive, which may help mold these subsequent interactions. Hence, physicians may need be more aware of their multifaceted roles, and gauge sensitively each patient's desires (i.e., for information and paternalism vs. autonomy), rather than adopt a generic "one size fits all" approach.

But obstacles exist to increasing doctors' relative non-directiveness. Medical educators may need to develop models to teach students how to be less directive, and when and to what degree to do so. Such questions need to be carefully considered and addressed. Concretely, the present data offer several possible suggestions. For example, physicians should at least consider discussing treatment alternatives with patients, even if then advising against these. Asking patients about their informational or other needs and experiences about these decisions can also be important. At times, it may be helpful for providers, friends and others who feel in a bind to discuss this predicament with patients (i.e., that failure to provide unequivocal input reflects not a lack wanting to do so, but inability to do so, due to these subjective ambiguities). 
Many women are understandably proactive, and think about possible eventual prophylactic surgeries even as they confront earlier testing and/or treatment decisions. Consequently, surgeons may need to be prepared to communicate with women about surgeries for not only treatment, but prophylaxis as well, and thus be ready and comfortable confronting the complexities and sensitivities involved.

Problems with communication found in these data reflect more general communication problems in health care [Klitzman, 2008]. However, at the same time, these data also highlight several specific and unique aspects of these decisions. Prophylactic surgery raises particular anxieties because the risks of both having surgery and not having it are considerable, yet abstract and hypothetical, and involve taboo issues concerning sexual organs, sexuality and physical attractiveness. Physicians often have difficulty discussing these areas fully and openly with patients [Klitzman, 2008]. In addition, physicians often have low understandings of genetics [Suther Menasha et al., 2000; Chase et al., 2002; Schroy et al., 2002; Barrison et al., 2003; Freedman et al., 2003; Baars et al., 2005; Burke et al., 2006]. Thus, medical education may benefit from addressing these areas more fully.

These data have implications as well for research — to address how to help patients understand these uncertainties and questions. In part, clinical studies are required to clarify how long women can wait before undergoing oophorectomies. Yet studies can also explore how providers, patients, family members, friends and others approach these ambiguities, and differ in doing so. Individuals may vary in either too readily seeking to minimize such ambiguity, or taking aggressive stances despite it, which may be perceived by others as callousness. Future research can help clarify these variations, and factors that may be associated with these. For instance, one factor, toleration of ambiguity, has recently received some attention [Geller et al., 1993], and has been found to be associated with physician socio-demographics (e.g., specialty, age, and race), hypothetical questions about genetic testing, and certain clinical decisions [Tubbs et al., 2006]. Yet many aspects of medical and surgical decision-making remain relatively unexamined (e.g., regarding relationships and types and patterns of communications). Physicians may be better trained in objective than in subjective considerations, but need to handle both.

More research can help clarify what factors predict what, how and when providers communicate with patients about these issues, and with what results. While much research has examined aspects of doctor-patient communication in a binary way (i.e., as present or absent), these data suggest the multiple complexities involved, related to not just whether doctors communicate information or not, but what, when, how and why they do so. While physicians may see themselves as simply "conveying the facts," the data here highlight the complex inter-related dynamic issues entailed. Future research can assess the degrees to which physicians appreciate these issues and needs for flexibility, and vary their approaches between patients. The degrees to which patients' and providers' respective perceptions of their mutual interactions may predict patient treatment decisions and outcomes can also be assessed. Given shortages of genetic counselors, doctors may benefit from becoming more involved in these communications, but may need to change their approaches. Questions remain, however, of how providers should best assess individual patients' concerns and preferences, and convey the complexities involved, what kind of language and approaches doctors do and should use-for example, to reflect not just paternalism versus nondirectiveness, but more in-between, nuanced, and flexible models.

It is unclear, too, how physicians do and should interface with other sets of patients' social inputs - whether physicians ever do or should refer patients to on-line sites, and if so, which when, why, and with what results. Research is needed as well on how exactly women decide how involved to be in breast cancer communities, and what information they seek 
concerning these and other decisions, how these communities affect these choices, what relevant information various on-line breast cancer communities and websites provide, and how accurate and unbiased it is. Commercial medical sites focused on other diseases have been found often to be biased-presenting benefits of interventions far more than risks [Klitzman et al., 2009]. In on-line breast cancer support groups, active participation has been found to be associated with being white, having a higher energy level, and having a more positive relation with one's physician [Shaw et al., 2006]. For several diseases, studies of the content of on-line communities have found that most messages involved informational and emotional support [Coulson et al., 2007]. Breast cancer websites may decrease the medical profession's “information monopoly" [Radin, 2006]. For fibromyalgia, one on-line support group was found to challenge physician expertise [Barker, 2008]. For prophylactic surgery for breast and ovarian cancer, whether biases or inaccuracies or distrust of physicians exist, and if so, how often, and in what ways remain unknown. Particular groups or sites may demonstrate biases one way or the other. For example, dissatisfied patients more than others may express their opinions. Future research can examine these issues as well. Similarly, future studies can explore how often women may seek on-line information either to support their own prior preferences, or find new information that may alter their prior attitudes. Such research can assess which women seek which type of information, and with what results. Questions arise, too, as to how to enable breast cancer communities and providers to work best together.

These data also suggest needs to investigate more fully how, and to what degrees the difficulties in communication described here may affect patients' eventual clinical decisions. Enhanced physician ability to communicate sensitively with patients (e.g., gauging what and when to communicate) can potentially help women make optimal decisions about these surgeries. These decisions involve complex pros and cons. Extents of family histories, and thus of risk, vary widely. Hence, it is difficult to say how many women should ideally undergo surgeries. But the evidence seems to suggest that many women who might benefit from these procedures do not now undergo them. Most importantly, it is critical that patients make decisions that are as informed and appropriate as possible, with all of the questions they confront addressed as sensitively as possible by providers.

These data have implications, too, for policy makers at health care institutions, insurance companies and governmental agencies: to consider ways of facilitating optimal provider communication. Physicians face multiple competing demands for their time, challenging their ability to be optimally sensitive and empathetic. Reduced reimbursement rates add to these pressures. Hence, improving insurance coverage to enable providers to have more time to discuss these issues with patients can be vital. Potentially, on-line websites and information can be developed with professional input to assist patients in addressing these quandaries. In the long run, such efforts can potentially improve disease prevention and medical outcomes.

From a theoretical perspective, these data illustrate the ways and degrees to which interactions with physicians and others can shape key elements of the Health Belief Model and the State of Change Model—specifically, awareness of treatment options and perceived susceptibility. Clearly, these external inputs vary widely. Hence, it is important for future research to explore more thoroughly aspects of these interactions as described here.

These data have several limitations. These women reported as best as they could their perceptions and recollections of physicians' comments, but may at times not have recalled physicians' comments verbatim or wholly accurately. Nonetheless, in the least, these women's perceptions, memories, responses and attitudes are important in and of themselves in revealing their perspectives on interactions, and their concerns, which can prove critical. 
Future research can attempt to explore matched dyads of patients with their actual providers. In addition, these women provided data at one point in time, and spoke about past decisions and operations. But these data nevertheless offer insights that future research can examine further, longitudinally. The sample size, though relatively low for quantitative studies, is sufficient for qualitative research, providing an in-depth sense of the range and types of issues and phenomena that arise here. Future research can explore these issues in larger samples, too. We have also included a range of women, both tested and untested, and those who have not yet decided to undergo prophylactic surgery, or decided against it. Though a critic may object that this breadth is too diverse, we found that these women were generally aware of these issues and commented on them from their respective vantage points. For example, wariness of prophylactic surgery led some women even to avoid testing, since they felt they could thereby avoid having to confront these stressful surgical dilemmas.

In sum, these data illuminate a series of quandaries these patients confront, and crucial roles that providers and others may play in addressing these dilemmas. As such, these results have several possible implications for enhancing provider training and care, education of patients and their families, and future research and policy.

\section{Acknowledgments}

This research was funded from a grant from the ELSI program of the National Human Genome Research Institute (ROI-HG002431-01). I would like to thank Dr. Victor Grann and Dr. Ruby Senie, and Carolyn Kumah for valuable assistance with recruiting participants, and Melissa Conley, Kristen Nelson, and Lisa Chin for their assistance with the manuscript.

\section{REFERENCES}

American Board of Genetic Counseling. [Accessed June 16, 2008] 2008. http://www.abgc.net/english/View.asp?x=1607

Anderson K, Jacobson JS, Heitjan DF, Graff Zivin J, Hershman D, Neugut AI, Grann VR. Costeffectiveness of preventive strategies for women with BRCA1 or BRCA2 mutation. Ann Intern Med. 2006; 144:397-406. [PubMed: 16549852]

Antill Y, Reynolds J, Young M, Kirk J, Tucker K, Bogtstra T, Wong S, Dudding T, Di Iulio J, Phillips K. Risk-reducing surgery in women with family susceptibility for breast and/or ovarian cancer. Eur J Cancer. 2006; 42:621-628. [PubMed: 16434187]

Baars MJH, Henneman L, ten Kate LP. Deficiency of knowledge of genetics and genetic tests among general practitioners, gynecologists, and pediatricians: A global problem. Genet Med. 2005; 7:605610. [PubMed: 16301861]

Barker KK. Electronic support groups, patient-consumers, and medicalization: The case of contested illness. J Health Soc Behav. 2008; 49:20-36. [PubMed: 18418983]

Barrison AF, Smith C, Oviedo J, Heeren T, Schroy PC III. Colorectal cancer screening and familial risk: A survey of internal medicine residents' knowledge and practice patterns. Am J Gastroenterol. 2003; 7:605-610.

Bermejo-Perez MJ, Marquez-Calderon S, Llanos-Mendez A. Effectiveness of preventive interventions in BRCA 1/2 gene mutation carriers: A systematic review. Int J Cancer. 2007; 121:225-231. [PubMed: 17471565]

Botkin JR, Smith KR, Croyle RT, Baty BJ, Wylie JE, Dutson D, Chan A, Hamann HA, Lerman C, McDonald J, Venne V, Ward JH, Lyon E. Genetic testing for a BRCA 1 mutation: Prophylactic surgery and screening behavior in women 2 years post testing. Am J Med Genet Part A. 2003; 118A:201-209. [PubMed: 12673648]

Bradbury AR, Ibe CN, Dignam JJ, Cummings SA, Verp M, White MA, Artioli G, Dudlicek L, Olopade OI. Uptake and timing of bilateral prophylactic salpingo-oophorectomy among BRCA 1 and BRCA 2 mutation carriers. Genet Med. 2008; 10:161-166. [PubMed: 18344704] 
Burke S, Stone A, Bedward J, Thomas H, Farridon P. A "neglected part of the curriculum" or "of limited use"? Views on genetics training by nongenetics medical trainees and implications for delivery. Genet Med. 2006; 8:109-115. [PubMed: 16481894]

Chase GA, Geller G, Havstad SL, Holtzman NA, Bassett SS. Physicians' propensity to offer genetic testing for Alzheimer's disease: Results from a survey. Genet Med. 2002; 4:297-303. [PubMed: 12172396]

Coulson NS, Buchanan H, Aubeeluck A. Social support in cyber-space: A content analysis of communication within a Huntington's disease on-line support group. Patient Educ Couns. 2007; 68:173-178. [PubMed: 17629440]

Cox SM, McKellin W. "There's this thing in our family": Predictive testing and the construction of risk for Huntington disease. Sociol Health Illn. 1999; 21:622-646.

Freedman AN, Wideroff L, Olson L, Davis W, Klabunde C, Srinath KP, Reeve BB, Croyle RT, Ballard-Barbash R. US physicians' attitudes toward genetic testing for cancer susceptibility. Am J Med Genet Part A. 2003; 120A:63-71. [PubMed: 12794694]

Geertz, C. Interpretation of cultures: Selected essays. New York: Basic Books; 1973. p. 470

Geller G, Tambor ES, Chase GA, Holtzman NA. "Measuring physicians' tolerance for ambiguity and its relationship to their reported practices regarding genetic testing". Med Care. 1993; 31:9891001. [PubMed: 8231339]

Gifford, SM. The meanings of lumps: A case study of the ambiguities of risk. In: James, CR.; Stall, R.; Gifford, SM., editors. Anthropology and epidemiology. Holland: D. Reidel Publishing Comp.; 1986. p. 213-246.

Graves KD, Peshkin BN, Halbert CH, DeMarco TA, Isaacs C, Schwartz MD. Predictors and outcomes of contralateral prophylactic mastectomy among breast cancer survivors. Breast Cancer Res Treat. 2007; 104:321-329. [PubMed: 17066320]

Guest G, Bunce A, Johnson L. How many interviews are enough? An experiment with data saturation and variability. Field Methods. 2006; 18:59-82.

Hallowell N, Jacobs I, Richards M, Mackay J, Gore M. Surveillance or surgery? A description of the factors that influence high risk premenopausal women's decisions about prophylactic oophorectomy. J Med Genet. 2001; 1:683-726. [PubMed: 11594337]

Helmes AW. Application of the protection motivation theory to genetic testing for breast cancer risk. Prev Med. 2002; 35:453-462. [PubMed: 12431894]

Houn F, Helzlsouer KJ, Friedman NB, Stefanek ME. The Practice of prophylactic mastectomy: A survey of Maryland surgeons. Am J Public Health. 1995; 85:801-805. [PubMed: 7762713]

Julian-Reynier C, Eisinger F, Moatti JP, Sobol H. Physicians' attitudes towards mammography and prophylactic surgery for hereditary breast/ovarian cancer risk and subsequently published guidelines. Eur J Hum Genet. 2000; 8:204-208. [PubMed: 10780786]

Kaufman EM, Peshkin BN, Lawrence WF, Shelby R, Isaacs C, Brown K, Rispoli J, O’Neill S, Hurley K, DeMarco T, Brogan B, Grumet S, Jandorf L, McKenna K, Valdimarsdottir H, Schwartz MD. Development of an interactive decision aid for female BRCA 1/BRCA 2 carriers. J Genet Carriers. $2003 ; 12: 109-129$.

Kaut KP. Counseling psychology in the era of genetic testing: Considerations for practice, research, and training. Counseling Psychologist. 2006; 34:461-488.

Kinney AY, Simonsen SE, Baty BJ, Mandal D, Neuhausen SL, Seggar K, Rolubkov R, Bloor L, Smith $\mathrm{K}$. Risk reduction behaviors and provider communication following genetic counseling and $B R C A$ 1 mutation testing in an African American Kindred. J Genet Couns. 2006; 15:293-305. [PubMed: 16865561]

Klitzman, R. When doctors become patients. New York: Oxford University Press; 2008. p. 333

Klitzman R, Thorne D, Williamson J, Chung W, Marder K. Decision-making about reproductive choices among individuals at-risk for Huntington's Disease. J Genet Couns. 2007a; 16:347-362. [PubMed: 17473962]

Klitzman R, Thorne D, Williamson J, Marder K. The roles of family members, health care workers and others in decision-making processes about genetic testing among individuals at risk for Huntington's Disease. Genet Med. 2007b; 9:358-371. [PubMed: 17575502] 
Klitzman R, Thorne D, Williamson J, Chung W, Marder K. Disclosures of Huntington's Disease risk within families: Patterns of decision-making and implications. Am J Med Genet Part A. 2007c; 143A:1835-1849. [PubMed: 17632780]

Klitzman R, Albala I, Siragusa J, Appelbaum P. Disclosure of information to potential subjects on research recruitment websites. IRB. 2008; 30:15-20. [PubMed: 18306955]

Klitzman R, Zolovska B, Folberth W, Chung W, Sauer M, Appelbaum P. Presentations on IVF clinic websites of information on pre-implantation genetic diagnosis: Ethics, risks and benefits. Fertil Steril. 2009; 92:1276-1283. [PubMed: 18829009]

Kram V, Peretz T, Sagi M. Acceptance of preventive surgeries by Israeli women who had undergone BRCA testing. Fam Cancer. 2006; 5:327-335. [PubMed: 16724248]

Lerman C, Hughes C, Croyle RT, Main D, Durham C, Snyder C, Bonney A, Lynch JF, Narod SA, Lynch HT. Prophylactic surgery decisions and surveillance practices one year following BRCA $1 / 2$ testing. Prev Med. 2000; 31:75-80. [PubMed: 10896846]

Lobb EA, Butow PN, Moore A, Barratt A, Tucker K, Gaff C, Kirk J, Dudding T, Butt D. Development of a communication aid to facilitate risk communication in consultations with unaffected women from high risk breast cancer families: A pilot study. J Genet Couns. 2006; 15:393-405. [PubMed: 16967332]

Madalinksa JB, van Beurden M, Bleiker EMA, Valdimarsdottir HB, Lubsen-Brandsma L, Massuger LF, Mourits MJE, Gaarenstroom KN, van Dorst EBL, van der Putten H, Boonstra H, Aaronson NK. Predictors of prophylactic bilateral salpingo-oophorectomy compared with gynecologic screening use in BRCA 1/2 mutation carriers. J Clin Oncol. 2007; 25:301-307. [PubMed: 17235045]

Meijers-Heijboer EJ, Verhoog LC, Brekelmans CTM, Seynaeve C, Tilanus-Linthorst MMA, Wagner A, Dukel L, Devilee P, van den Ouweland AMW, van Geel AN, Klijn JGM. Presymptomatic DNA testing and prophylactic surgery in families with a BRCA 1 or BRCA2 mutation. Lancet. 2000; 355:2015-2020. [PubMed: 10885351]

Meiser B, Tiller K, Gleeson MA, Andrews L, Robertson G, Tucker KM. Psychological impact of prophylactic oophorectomy in women at increased risk for ovarian cancer. Psycho-Oncology. 2000; 9:496-503. [PubMed: 11180584]

Metcalfe KA, Snyder C, Seidel J, Hanna D, Lynch HT, Narod S. The use of preventive measures among healthy women who carry a BRCA1 or BRCA2 mutation. Fam Cancer. 2005; 4:97-103. [PubMed: 15951959]

Metcalfe KA, Ghadirian P, Rosen B, Foulkes W, Kim-Sing C, Eisen A, Ainsworth P, Horsman D, Maugard C, Provencher D, Robideaux A, Gilchrist D, Chudley A, Lemire EG, Armel S, Finch A, Ping S, Narod SA. Variation in rates of uptake of preventive options by Canadian women carrying the BRCA1 or BRCA2 genetic mutation. Open Med. 2007; 1:92-98.

Metcalfe KA, Birenbaum-Carmeli D, Lubinski J, Gronwald J, Lynch H, Moller P, Ghardirian P, Foulkes WD, Klijn J, Friedman E, Kim-Sing C, Ainsworth P, Rosen B, Domchek S, Wagner T, Tung N, Manoukian S, Couch F, Sun P, Narod SA. The Hereditary Breast Cancer Clinical Study Group. International variation in rates of uptake of preventive options in BRCA 1 and BRCA2 mutation carriers. Int J Cancer. 2008a; 122:2017-2022. [PubMed: 18196574]

Metcalfe KA, Lubinkski J, Ghadirian P, Lynch H, Kim-Sing C, Friedman E, Foulkes WD, Domchek S, Ainsworth P, Isaacs C, Tung N, Gronwald J, Cummings S, Wagner T, Manoukian S, Møller P, Weitzel J, Sun P, Narod SA. Predictors of contralateral prophylactic mastectomy in women with BRCA 1 or BRCA 2 mutation: The hereditary breast cancer clinical study group. J Clin Oncol. 2008b; 26:1093-1097. [PubMed: 18195327]

Miller SM, Roussi P, Daly MB, Buzaglo JS, Sherman K, Godwin A, Balshem A, Atchison ME. Enhanced counseling for women undergoing BRCA 1/2 testing: Impact on subsequent decision making about risk reduction behaviors. Health Educ Behav. 2005; 32:654-667. [PubMed: 16148211]

Payne DK, Biggs C, Tran KN, Borgen PI, Massie MJ. Women's regrets after bilateral prophylatic mastectomy. Ann Surg Oncol. 2000; 7:150-154. [PubMed: 10761795]

Prochaska JO, DiClemente CC, Norcross JC. In search of how people change: Applications to addictive behaviors. Am Psychol. 1992; 47:1102-1114. [PubMed: 1329589] 
Radin P. "To me, it's my life": Medical communication, trust, and activism in cyberspace. Soc Sci Med. 2006; 62:591-601. [PubMed: 16039031]

Ray JA, Loescher LJ, Brewer M. Risk-reduction surgery decisions in high-risk women seen for genetic counseling. J Genet Couns. 2005; 14:473-484. [PubMed: 16388328]

Rosenstock IM, Strecher VJ, Becker MH. Social learning theory and the health belief model. Health Educ Q. 1988; 15:175-183. [PubMed: 3378902]

Schroy PC, Barrison AF, Ling BS, Wilson S, Geller AC. Family history and colorectal cancer screening: A survey of physician knowledge and practice patterns. Am J Gastroenterol. 2002; 97:1031-1036. [PubMed: 12008667]

Schwartz MD, Kaufman E, Peshkin BN, Isaacs C, Hughes C, DeMarco T, Finch C, Lerman C. Bilateral prophylactic oophorectomy and ovarian cancer screening following BRCA1/BRCA2 mutation testing. J Clin Oncol. 2003; 21:4034-4041. [PubMed: 14581427]

Shaw BR, Hawkins R, Arora N, McTavish F, Pingree S, Gustafson DH. An exploratory study of predictors of participation in a computer support group for women with breast cancer. Comput Inform Nursing. 2006; 24:18-27.

Strauss, A.; Corbin, J. Basics of qualitative research-Techniques and procedures for developing grounded theory. Newbury Park: Sage Publications; 1990. p. 323

Suther Menasha JD, Schechter C, Willner J. Genetic testing: A physician's perspective. Mt Sinai J Med. 2000; 67:144-151. [PubMed: 10747371]

Tiller K, Meiser B, Butow P, Clifton M, Thewes B, Friedlander M, Tucker K. Psychological impact of prophylactic oophorectomy in women at increased risk of developing ovarian cancer: A prospective study. Gynecol Oncol. 2002; 86:212-219. [PubMed: 12144830]

Tubbs EP, Broeckel Elrod J, Flum DR. Risk taking and tolerance of uncertainty: Implications for surgeons. J Surg Res. 2006; 131:1-6. [PubMed: 16085105]

van Dijk S, Otten W, Zoeteweij MW, Timmermans DRM, van Asperen CJ, Breuning MH, Tollenaar RAEM, Kievit J. Genetic counseling and the intention to undergo prophylactic mastectomy: Effects of a breast cancer risk assessment. Br J Cancer. 2003; 88:1675-1681. [PubMed: 12771979] 


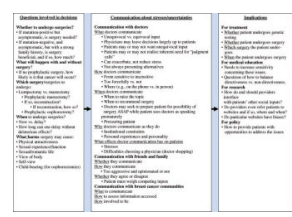

FIG. 1.

Decisions about prophylactic surgery: relationships between questions involved in communication, and treatment implications. 


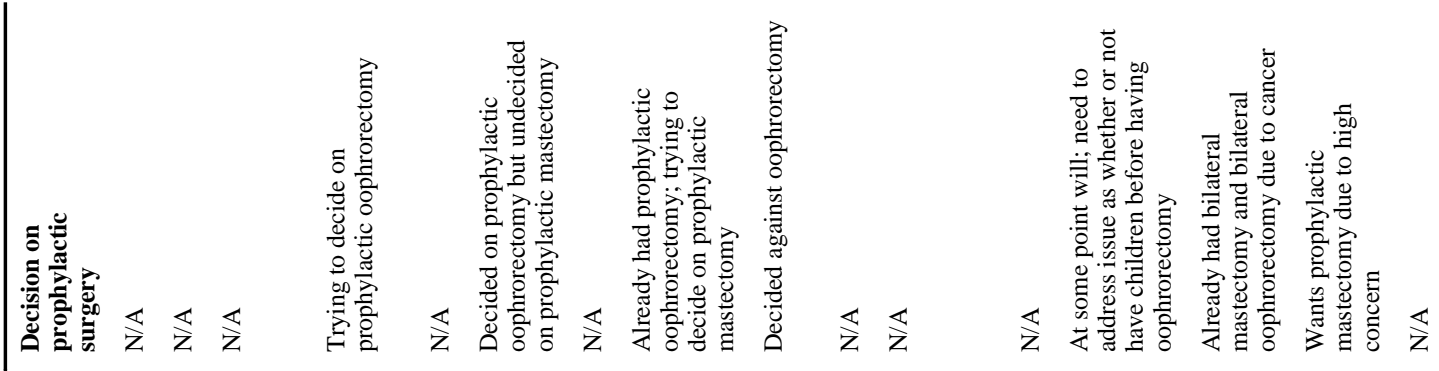

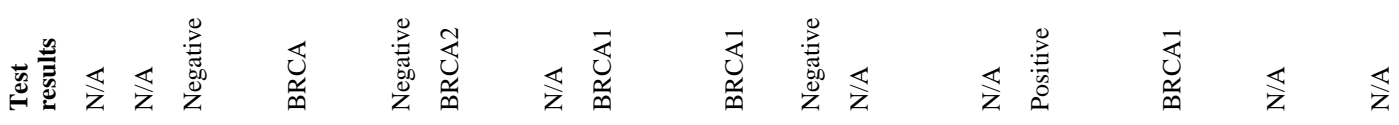

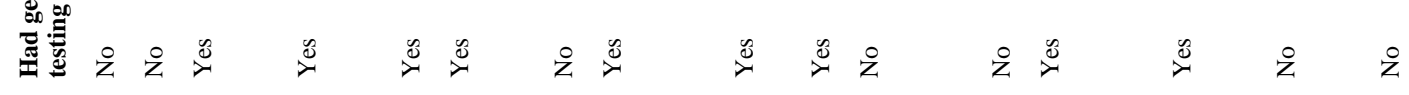

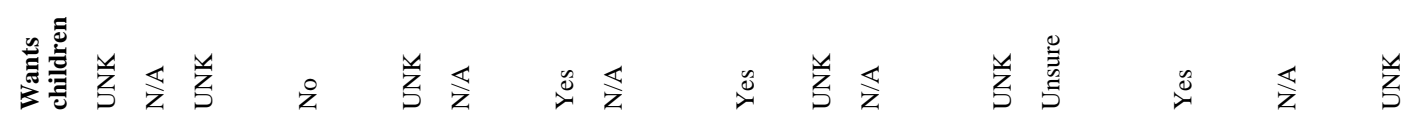
竧

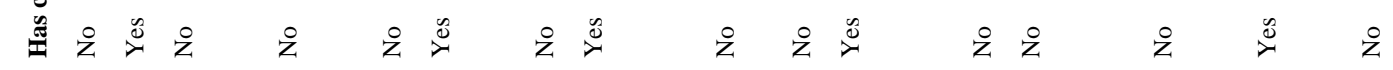

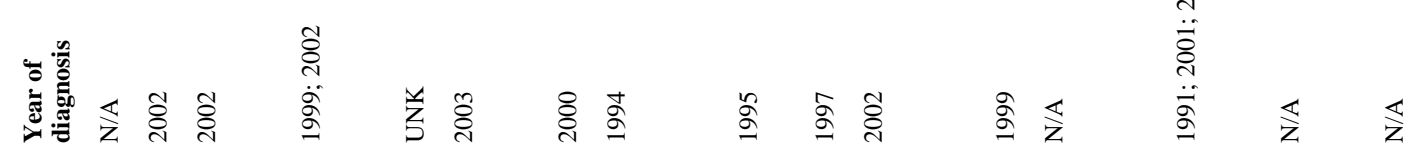

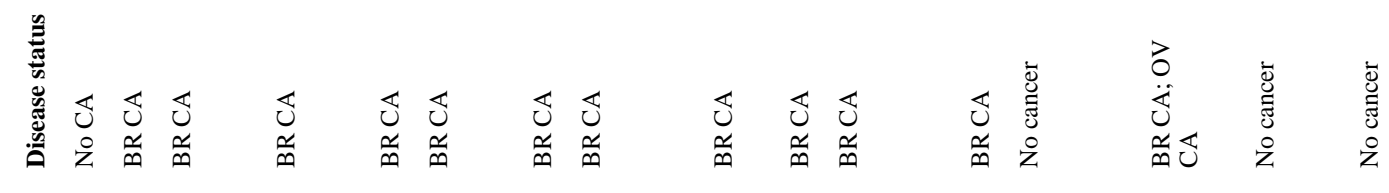




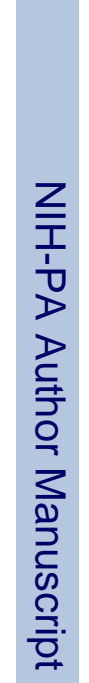

Wo.

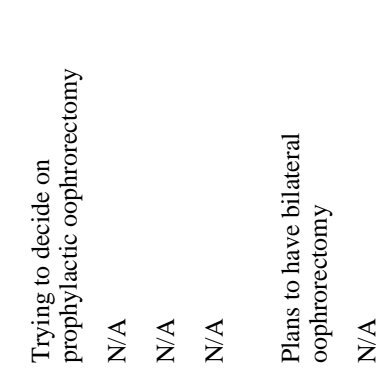

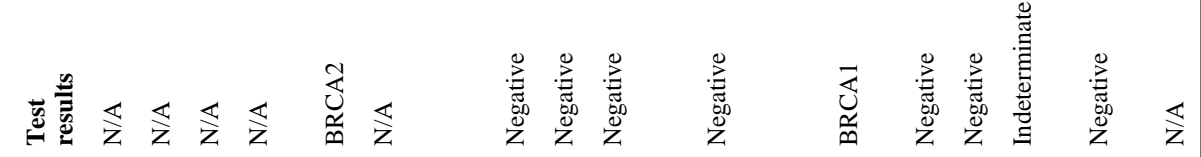

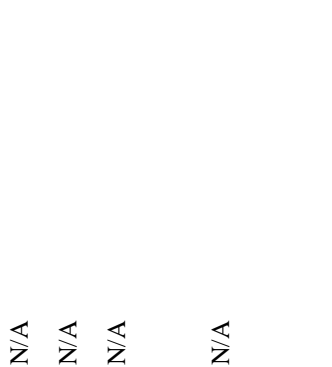

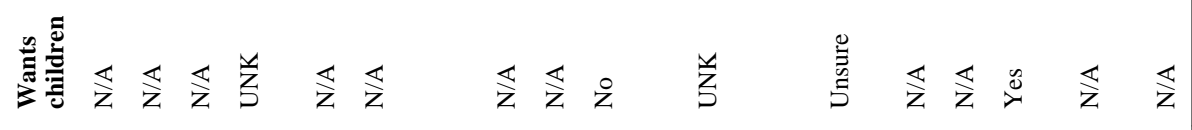
童

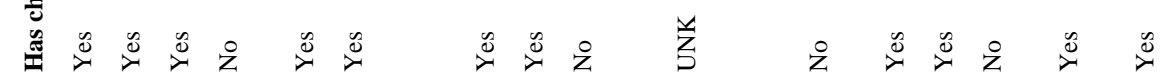

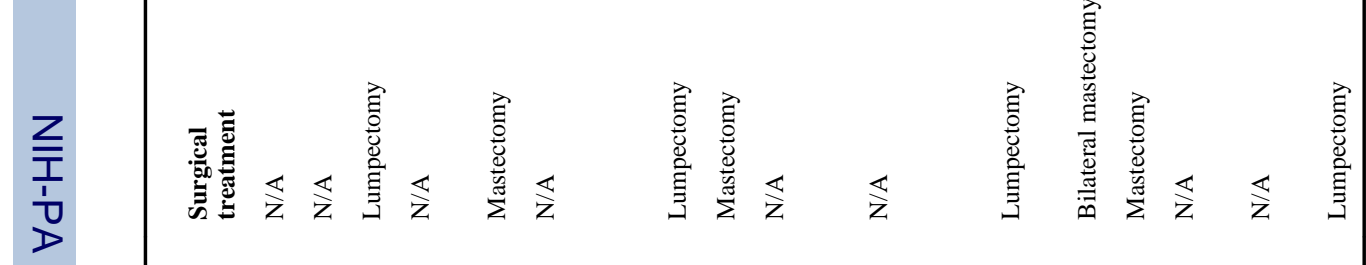

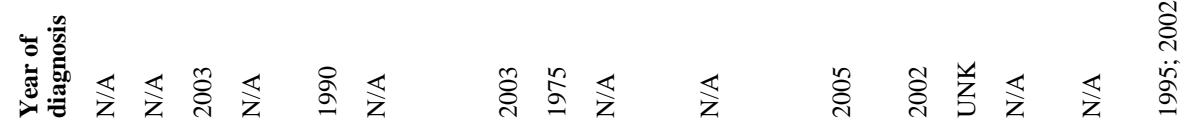

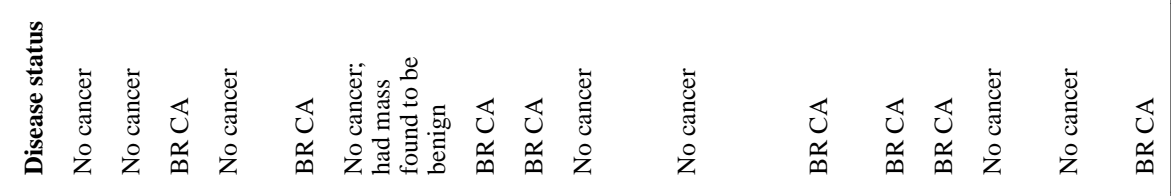

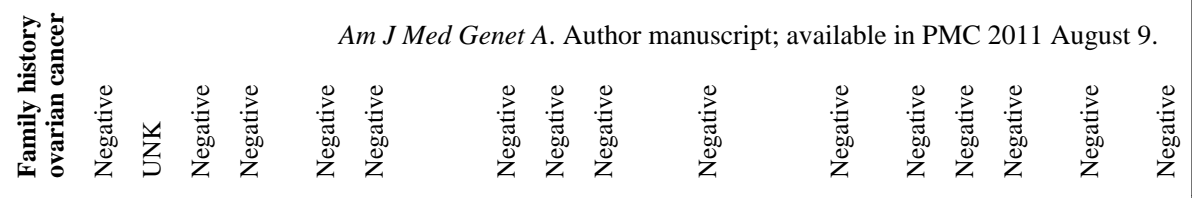

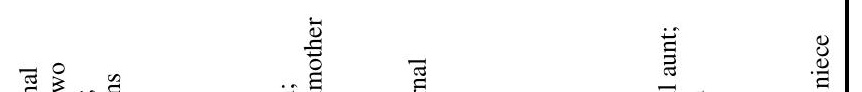




\section{TABLE II}

Semi-Structured Interview Guide (Sample Questions)

Have you considered or pursued any treatment or surgery for breast cancer or risk of breast cancer? If so, what and why?
How did you make those decisions?
Have healthcare providers discussed treatment issues with you? If so, what did they say?
Have you discussed treatment issues with any other people?
If so, who, when and why? What did they say?
How do you feel about interactions you have had with providers and others about these issues? 